Int. J. Electrochem. Sci., 11 (2016) 4037 - 4049

\title{
Structural Analysis of Enhanced Ferroelectricity in Nano- Composite Films of Sodium Nitrite in poly-Vinyl Alcohol Matrix Fabricated at Moderate Elevated Temperature
}

\author{
Lakhbir Singh ${ }^{1,2,6}$, Baljinder Kaur ${ }^{1,2,6}$, Neeraj Kumar ${ }^{3}$, Dae-Yong Jeong ${ }^{4}$, Navneet Dabra ${ }^{5,}$, \\ Jasbir S.Hundal \\ ${ }^{1}$ Department of YCoE Punjabi University Guru Kashi Campus Talwandi Sabo-151302, Punjab, India \\ ${ }^{2}$ Research Scholar, IK Gujral Punjab Technical University Kapurthala-144001, Punjab, India \\ ${ }^{3}$ Department of Physics, Amity University, Jaipur -302006, Rajasthan, India \\ ${ }^{4}$ Department of Materials Science and Engineering, Inha University, Incheon-402-751, Republic of \\ Korea \\ ${ }^{5}$ Mata Sahib Kaur Girls College (affiliated to Punjabi University Patiala), Talwandi Sabo-151302, \\ Punjab, India \\ ${ }^{6}$ Materials Science Laboratory, Department of Applied Physics, Giani Zail Singh Campus College of \\ Engineering and Technology, MRS State Technical University Bathinda-151001, Punjab, India \\ *E-mail: navneetdabra@gmail.com
}

doi: $10.20964 / 110354$

Received: 10 January 2016 / Accepted: 8 March 2016 / Published: 1 April 2016

In the present study, various composite films of $\mathrm{NaNO}_{2}$-PVA differing in their weight percentage composition have been prepared on brass substrates by solvent drop cast method at optimized elevated temperature of $70{ }^{\circ} \mathrm{C}$. Improved ferroelectric response was observed in the films with equal weight percentage composition giving remanant polarization, $P_{\mathbf{r}} \sim 45.45 \mu \mathrm{C} / \mathrm{cm}^{2}$. The peak polarization current density $\mathbf{J}_{\max }$ was also maximum for this composition with measured value of $\mathrm{J}_{\max }=+6.13 \times 10^{-}$ ${ }^{2} \mathrm{~A} / \mathrm{cm}^{2}$ at $3.09 \mathrm{kV} / \mathrm{cm}$ and $\mathrm{J}_{\max }=-6.13 \times 10^{-2} \mathrm{~A} / \mathrm{cm}^{2}$ at $-2.68 \mathrm{kV} / \mathrm{cm}$. The average crystallite size calculated using Scherrer relation was found to be lying in the nano-scale range. This calculated value from XRD studies was in good agreement with the particle size observed with transmission electron microscopy (TEM). The minimum strain $\sim 0.62 \%$ and increased b/a ratio $\sim 1.6269$ in the $\mathrm{NaNO}_{2}-$ PVA nano-composite film containing equal weight percentage might have improved the ferroelectric phase of the nano-composite system exhibiting improved remanant polarization.

Keywords: Ferroelectricity, $\mathrm{NaNO}_{2}$-PVA composite-films, XRD, strain, crystallite size, TEM 
(C) 2016 The Authors. Published by ESG (www.electrochemsci.org). This article is an open access article distributed under the terms and conditions of the Creative Commons Attribution license (http://creativecommons.org/licenses/by/4.0/). 